\title{
The position of theophylline in the treatment of asthma and chronic obstructive pulmonary disease
}

\author{
P.N.R. Dekhuijzen, H.F.M. van der Heijden, C.L.A. van Herwaarden \\ Department of Pulmonary Diseases, University Hospital, P.B. 9101, 6500 HB Nijmegen, Netherlands
}

Keywords: Theophylline; Asthma; Chronic obstructive pulmonary disease

\section{Introduction}

For many years theophylline was a first-line drug in the treatment of patients with asthma and chronic obstructive pulmonary disease (COPD). Its role, however, has diminished because of the recognition of inflammation, and hence antiinflammatory therapy, as a hallmark of asthma. Moreover, the development of long-acting $\beta_{2^{-}}$ sympaticomimetics has led to a shift backwards of theophylline to a third-line choice of treatment in the current guidelines of the treatment of these diseases $[1,2]$. This was augmented by its narrow therapeutic range, toxic side-effects and interactions with other medications.

On the other hand, the introduction of slowrelease preparations and the low price of the drug have favoured its use. In addition, recent studies have suggested that theophylline posesses anti-inflammatory activities at low serum levels that might be of clinical relevance in patients with acute or chronic asthma. Other modes of action may favour the use of theophylline in patients with COPD such as its stimulating effect on ventilation and its positive inotropic effects on the respiratory muscles.

In this article we will address some clinical issues with regard to treatment with theophylline as well as the consequences for its current and future position in the treatment of patients with asthma and COPD.

\section{Bronchodilating effect of theophylline com- pared to the long-acting $\beta_{2}$-sympathicomimetics}

One of the potential beneficial effects of slow-release preparations of theophylline is its ability to produce sustained bronchodilation during the night. A similar effect has been ascribed to the new long-acting $\beta_{2}$-sympathicomimetics, i.e. formoterol and salmeterol. A few comparative studies have been performed. The effects of 2-4 weeks treatment with theophylline slow-release tablets and salmeterol were compared in asthmatics with nocturnal symptoms [3]. Salmeterol was superior to theophylline with regard to lung function, nocturnal awakenings and side-effects. In a similar group of patients salmeterol showed better effects on nocturnal symptoms and fewer side-effects than slow-release theophylline combined with ketotifen [4]. In addition, salmeterol reduced the number of additional short-acting $\beta_{2}$-agonists needed [5].

In conclusion, long-acting $\beta_{2}$-sympathicomimetics appear to have better protective effects 
during the night than theophylline. Studies investigating possible additional effects of theophylline combined with long-acting $\beta_{2}$-agonists have not been performed to our knowledge.

\section{Anti-inflammatory properties of theophylline: its clinical relevance}

As recently summarised, several studies have demonstrated that theophylline may have anti-inflammatory effects in vitro [6]. These include decreased mediator release by mast cells, decreased release of reactive oxygen species by macrophages and neutrophils, diminished release of cytokines by monocytes, decreased release of basic protein and changes in the release of reactive oxygen species by eosinophils, and decreased proliferation and cytokine release by T-lymphocytes. Animal models in vivo showed a decreased late response to allergen, inhibition of plasma exudation, a decrease in airway responsiveness to allergen and platelet-activating factor, and a decrease in airway inflammation after challenge with endotoxin and allergen.

Limited data are now available on the immunomodulatory effects of theophylline in vivo in humans. Chronic administration of theophylline increases the number of suppressor T-cells $\left(\mathrm{CD} 8^{+}\right.$ cells) in peripheral blood of asthmatics. Theophylline also inhibits the late asthmatic reaction and the allergen-induced increase in $\mathrm{CD}^{+}$and $\mathrm{CD} 8^{+}$lymphocytes observed in peripheral blood 48 hours after allergen challenge [7].

Studies on the clinical efficacy in this respect are scarce. Dutoit and co-workers showed that treatment with theophylline for 3 weeks in severe asthmatics did not affect bronchial hyperresponsiveness measured by provocation with histamine, in contrast to beclomethasone dipropionate 800 $\mu \mathrm{g}$ daily [8]. A recent study demonstrated that withdrawal of theophylline (serum level less than $10 \mathrm{mg} / \mathrm{l})$ in asthmatics who all used inhaled corticosteroids resulted in an increase in nocturnal symptoms and peak flow variability and a fall in $\mathrm{FEV}_{1}$ by $10 \%$. This was accompanied by a fall in activated $\mathrm{CD}^{+}$and $\mathrm{CD} 8^{+}$lymphocytes in peripheral blood. Bronchial biopsies showed a mir- ror image of the peripheral blood changes, with an increase in activated $\mathrm{CD}^{+}$and $\mathrm{CD}^{+} \mathrm{T}$-cells during withdrawal of theophylline [6].

These findings suggest that theophylline inhibits the shift of T-lymphocytes from the circulation to the airways. The clinical significance of these immunomodulatory effects, however, is not yet clear.

\section{Effects of theophylline on respiratory muscle function}

An area of ongoing dispute is the question whether theophylline improves respiratory muscle function in humans. The studies by the group of Aubier and co-workers showed that theophylline improved respiratory muscle function in patients with COPD [9]. In this study the authors found an improvement in maximum oesophageal pressures, tidal volumes and blood gases. An effect of theophylline on "intrinsic" respiratory muscle strength, however, was not proven since these effects might also be explained by changes in trapped air volume and decreases in airway resistance. Many studies regarding this subject were conflicting, but most of them failed to show a beneficial effect of theophylline on respiratory muscle strength in healthy subjects and in COPD [10].

An interesting observation was made by Wanke and colleagues who examined the effects of theophylline on "fresh" and "exhausted" diaphragm in healthy subjects [11]. At several lung volumes the pressure generation by the "exhausted" diaphragm was improved by theophylline, whereas this drug had no effects on the contractility of the "fresh" diaphragm. Although the occurrence of "exhausted" diaphragm in COPD is not known, this finding might explain the beneficial effects of theophylline sometimes found in these patients.

Besides possibly improving respiratory muscle strength, studies in anaesthetized dogs have shown that theophylline may recruit expiratory muscles, in contrast to, e.g., salbutamol [12]. This is of potential interest since this would allow patients with COPD to divide the work of breathing performed by the respiratory muscles over 
both the inspiratory and expiratory muscles. Studies in this respect have not yet been performed.

\section{Theophylline in the treatment of acute severe asthma}

In patients with acute asthma, theophylline given intravenously is less effective than nebulized $\beta$-agonists [13]. In a meta-analysis of 13 acceptably designed clinical trials comparing nebulized $\beta$-agonists with or without added theophylline there was no overall beneficial effect of additional theophylline [14]. A similar conclusion can be drawn from two studies on acute exacerbations in children $[15,16]$. In these studies, however, children with impending respiratory failure (who might benefit most from theophylline) were excluded. In contrast, a recent study in adult asthmatics suggested that the use of theophylline in the emergency room reduced subsequent admissions to the hospital with acute asthma [17]. In another study the effects of (double-blind) administration of placebo or theophylline besides inhaled $\beta_{2}$-agonists were clinically judged by independent observers. The administration of theophylline resulted in fewer admissions on additional theophylline compared to placebo. Since spirometric responses were similar in both groups, other properties of theophylline may play a beneficial role in acute asthma.

These studies suggest that theophylline should not be added routinely to nebulized $\beta$-agonists in acute asthma. Moreover, the number of serious side-effects increases [18].

In conclusion, adding theophylline in acute asthma should only be performed if nebulized $\beta$-agonists do not result in a beneficial effect. Titrating the dose of theophylline on the basis of the current plasma theophylline level is necessary to avoid serious side-effects.

\section{The role of theophylline in perioperative treat- ment}

Upper abdominal surgery is frequently associated with pulmonary complications. Reductions in vital capacity and functional residual capacity and impaired diaphragmatic function lead to a restrictive ventilatory defect with microatelectasis and ventilation-perfusion inhomogeneities.

In a previous study theophylline was shown to reverse the reduction of diaphragmatic activity during quiet breathing after cholecystectomy via laparotomy [19]. Recently, theophylline was shown to improve inspiratory muscle strength 48 hours after cholecystectomy via laparotomy [20]. Expiratory muscle function and lung volumes did not change significantly after theophylline compared to placebo. Presumably this effect of theophylline was caused by its central stimulating action, reducing the phrenic nerve inhibition induced by cholecystectomy. Unfortunately, no data on efficacy with regard to reduction in postoperative complications induced by theophylline were given. Other placebo-controlled studies regarding the effects of theophylline in perioperative treatment have not been performed.

\section{Recommendations}

Based upon the above-mentioned considerations theophylline should be considered in the following situations:

(1) severe COPD and chronic respiratory failure; (2) uncontrolled severe asthma despite high doses of inhaled steroids and long-acting $\beta_{2}$-agonists; in cases of (1) and (2) a trial of theophylline should carefully be evaluated for both clinical and physiological benefits and side-effects;

(3) acute severe asthma with impending respiratory failure despite high doses of nebulized $\beta_{2}$ agonists and corticosteroids.

Its role in suppressing the inflammatory process in asthma is not yet clear enough to advocate its use in this situation. In addition, its efficacy in perioperative management is not yet documented well enough to recommend its use in all cases.

\section{References}

[1] British Thoracic Society, Research Unit of the Royal College of Physicians of London, King's Fund Centre, National Asthma Campaign. Guidelines for the manage- 
ment of asthma in adults. I. Chronic persistent asthma. Br Med J 1990;301:651-653.

[2] National Asthma Education Program, Expert Panel on the Management of Asthma, National Heart Lung, and Blood Institute. Guidelines for the diagnosis and management of asthma. J Allergy Clin Immunol 1991; 88: 425-534.

[3] Paggario PL. Salmeterol and sustained release theophylline: a comparison in asthmatic patients. Allergy 1992;47(suppl 12):348.

[4] Muir JF, Bertin L, Georges D, French Multicentre Study Group. Salmeterol versus slow-release theophylline combined with ketotifen in nocturnal asthma: a multicentre trial. Eur Respir J 1992;5:1197-1200.

[5] Palmer JBD. Salmeterol in clinical practice. Eur Respir Rev 1991;13:297-300.

[6] Barnes PJ, Pauwels RA. Theophylline in the management of asthma: time for reappraisal? Eur Respir J 1994;7:579-591.

[7] Ward AJ, McKenniff M, Evans JM, Page CP, Costello JF. Theophylline: an immunomodulatory role in asthma? Am Rev Respir Dis 1993;147:518-523.

[8] Dutoit JI, Salome CM, Woolcock AJ. Inhaled corticosteroids reduce the severity of bronchial hyperresponsiveness in asthma but oral theophylline does not. Am Rev Respir Dis 1987;136:1174-1178.

[9] Murciano D, Auclair M, Pariente R, Aubier M. A randomized, controlled trial of theophylline in patients with severe chronic obstructive pulmonary disease. $N$ Engl J Med 1989;320:1521-1525.

[10] Jenne JW. What role for theophylline? Thorax 1994:49:97-100.

[11] Wanke T, Merkle $M$, Zifko $U$, et al. The effect of aminophylline on the force-length characteristics of the diaphragm. Am J Respir Crit Care Med 1994;149:15451549.
[12] Decramer M, Deschepper K, Jiang TX, Derom E. Effects of aminophylline on respiratory muscle interaction. Am Rev Respir Dis 1991;144:797-802.

[13] Bowler SD, Mitchell CA, Armstrong JG. Nebulised fenoterol and iv aminophylline in acute severe asthma. Eur J Respir Dis 1987;70:280-283.

[14] Littenberg B. Aminophylline treatment in severe acute asthma. A meta-analysis. J Am Med Assoc 1988;259:1678-1684.

[15] Carter E, Cruz M, Chesrown S, Shieh G, Reilly K, Hendeles L. Efficacy of intravenously administered theophylline in children hospitalized with severe asthma. J Pediatr 1993;122:470-476.

[16] DiGiulio GA, Kercsmar CM, Krug SE, Alpert SE, Marx CM. Hospital treatment of asthma: lack of benefit from theophylline given in addition to nebulized albuterol and intravenously administered corticosteroid. J Pediatr 1993;122:464-469.

[17] Wrenn K, Slovis CM, Murphy F, Greenberg RS. Aminophylline therapy for acute bronchospastic disease in the emergency room. Ann Intern Med 1991;115:241-247.

[18] Siegel D, Sheppard D, Gelb A, Weinberg PF. Aminophylline increases the toxicity but not the efficacy of an inhaled $\beta$-adrenergic agonist in the treatment of acute exacerbations of asthma. Am Rev Respir Dis 1985;132:283-286.

[19] Dureuil B, Desmonts JM, Mankikian B, Prokocimar P. Effects of aminophylline on diaphragmatic dysfunction after upper abdominal surgery. Anesthesiology 1985;626:229-230.

[20] Siafakas NM, Stoubou A, Stathopoulou M, Haviaras V, Tzanakis N, Bouros D. Effect of aminophylline on respiratory muscle strength after upper abdominal surgery: a double blind study. Thorax 1993;48:693-697. 